\title{
Virtual HTS and Free Energy Calculation of Brazilian Natural Compounds Using OOMT as Pharmacological Targets Database
}

\author{
Ana Paula Carregal, Flávia V. Maciel, Juliano B. Carregal \& Alex G. Taranto
}

\section{Introduction}

The Virtual Screening (VS) methods are useful to perform in silico search of lead compounds in large data base. This methodology selects the compounds with the best interaction energies for performing biological assays. Considering the natural products are a major source of lead compounds, VS applied to them have great possibilities for the development of a new drugs ${ }^{1,2}$. In general, the first step in the development of a new drug is understanding of the molecular target of interest. The Our Own Molecular Targets (OOMT) is a bank of proteins containing selected molecular targets for cancer, malaria and dengue ${ }^{3}$. In this context, VS was carried out on natural compounds against molecular targets on OOMT for the identification of hits for diseases that require new therapeutic alternatives.

\section{Methods}

The Brazilian natural compounds database was obtained from ZINC platform ${ }^{4}$, which consist of 473 compounds deposited by State University of Feira de Santana. These compounds were selected for VS methodology applied on OOMT. The geometry of the compounds were optimized through the universal force field ${ }^{5}$ (UFF) implemented in the Gaussian $09 \mathrm{~W}^{6}$ software.

Next, docking calculation was performed against 36 receptors deposited on OOMT. The AutoDock Vina $^{7}$ software was used for docking simulation. The effectiveness of AutoDock Vina program and the affinity of the compounds were evaluated using the redocking methodology ${ }^{8}$. The intermolecular interactions were described by Discovery Studio ${ }^{9}$ software. The resultant binding energy of each natural compounds obtained from docking step was divided by the crystallographic binding energy generating $z$ values (Equation 1). Natural compounds with $z$ value equal or bigger than one will be sent for further biological assay ${ }^{10}$.

\section{$\delta=$ Natural compounds binding energy Crystallographic ligand binding energy}

Equation 1. Determination of $\delta$ values.

Then, drug-likeness property was calculated in DataWarrior ${ }^{11}$ program to select compounds with better pharmacokinetic properties ${ }^{12}$. Following, the previous Autodock Vina results were refinement by free energy calculations using Dock6 software. Hence, the natural compounds selected by the delta value and by the druglikeness were submitted to the calculation of molecular docking, energy minimization and molecular dynamics (MD) using Dock6 ${ }^{13}$ program. The system was minimized at 5000 cycles, and then 30000 MD steps were run at 310 $\mathrm{K}$, followed by a further 5000 cycles of minimization. These calculations were run for protein, the ligand and for the complex respectively. In this study were selected the three most promising ligands to describe the binding energy and intermolecular interactions. 


\section{Results and Discussion}

As a result of docking simulation among 473 ligands against 36 molecular targets generated 17028 complex ligand-receptor. The delta values showed the most of the natural compounds had a better binding energy than crystallographic ligand for various OOMT proteins. This allowed to identify the best molecular targets for this study. The highest $\delta$ values obtained were the molecular targets with PDB code: $1 \mathrm{~W} 6 \mathrm{M}, 2 \mathrm{QHN}$ and 3JYA. The $1 \mathrm{~W} 6 \mathrm{M}, 2 \mathrm{QHN}$ and 3JYA receptors are involved in cancer process. Figure 1 shows the tertiary structure of molecular targets complexed with docked ligands. As can be seen, the ligands ZINC69482333, ZINC01721695 and ZINC01557254 were able to binding to $1 \mathrm{~W} 6 \mathrm{M}, 2 \mathrm{QHN}$ and 3JYA, respectively.

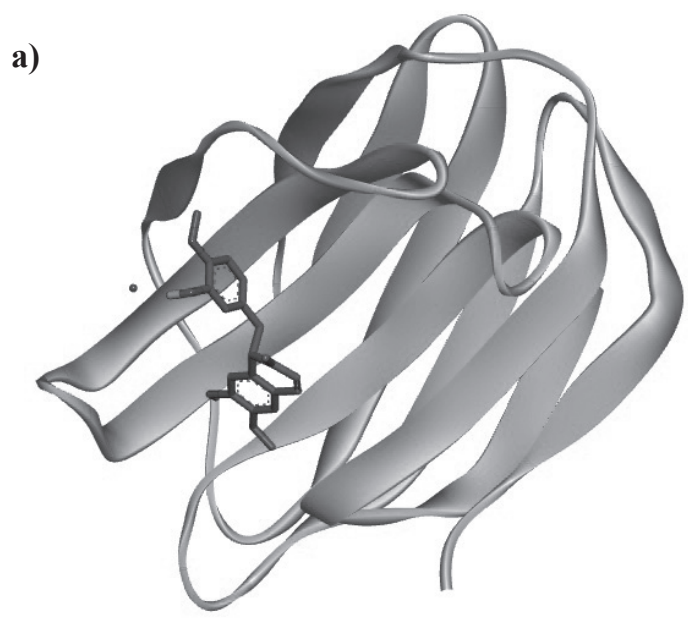

b)

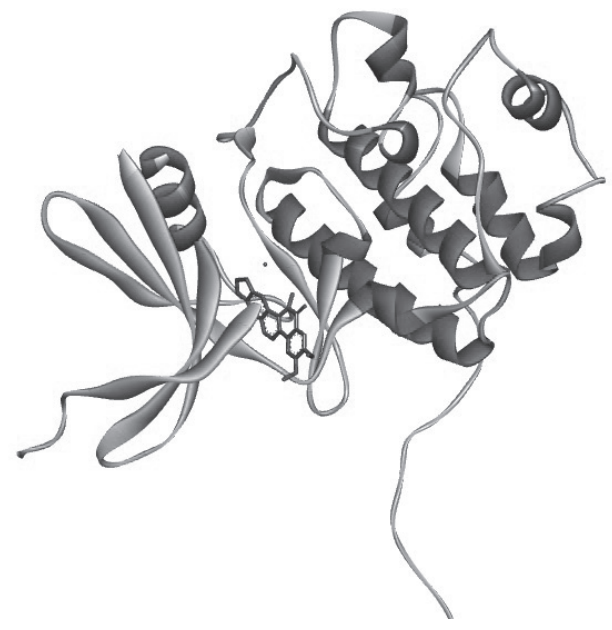

c)

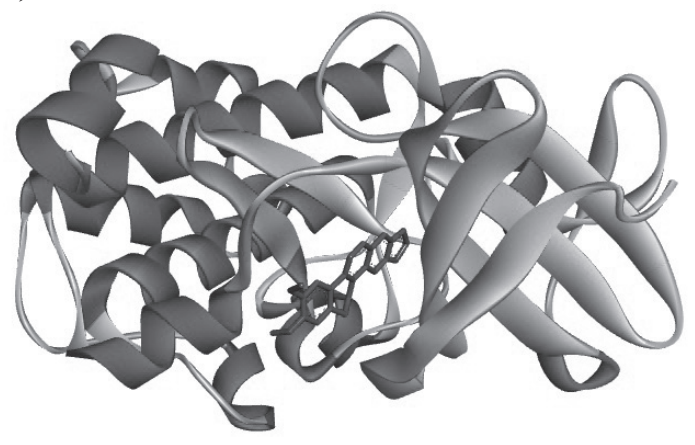

Figure 1. VS results of natural compounds on OOMT. a) Ligand ZINC69482333 complexed with 1W6M; b) Ligand ZINC01721695 complexed to the receptor 2QHN; c) Ligand ZINC01557254 complexed to $3 J Y A$.

In this study all molecular targets selected have involved in the cancer process. The $1 \mathrm{~W} 6 \mathrm{M}$ protein is involved in the regulation of cell migration. It has been associated with tumor malignancy. The possibility of the development of an inhibitor for this molecular target would result in inhibition of tumor migration ${ }^{14}$.

The $2 \mathrm{QHN}$ receptor, known as checkpoint kinase Chk1, performs the verification of the DNA and cell cycle delay for the cell to repair DNA. This function is carried out in conjunction with other proteins that in most cancers are inhibited. The Chk1 alone can not accomplish this DNA check function and cell death of cells with damaged DNA would be the best option to stop tumor growth. Inhibition of Chk1 stops the cell cycle leading it to death ${ }^{15}$.

The 3JYA protein is a cytoplasmic Pim kinase that controls programmed cell death by phosphorylation of substrates that regulate apoptosis and the cell metabolism. The pharmacological manipulation of these kinases may be useful for the treatment of various diseases such as cancer, inflammatory diseases and ischemic disorders ${ }^{16}$.

In addition to the $\delta$ values, druglikeness was used to select the best compounds. A positive value of druglikeness indicates that the molecule contains predominantly fragments which are frequently present in commercial drugs. Figure 2 shows the three ligands selected by the VS methodology and druglikeness. The ligands ZINC69482333, ZINC01721695 and ZINC01557254 showed druglikeness values of 2,14; 2,22 and 2,42 respectively. 


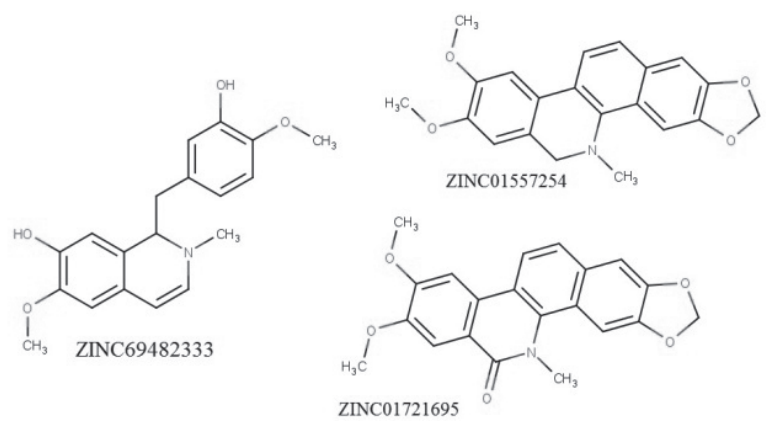

Figure 2. VS results of natural compounds on OOMT.

Summarising the VS results, table 1 shows the binding energy and delta values for ZINC69482333, ZINC01721695 and ZINC01557254 ligands against 1W6M, 2QHN and 3JYA molecular targets.

The binding energy of the complex was determined by three methods, the first one using the AutoDock Vina and the others through Dock6 (Grid and Amber Score Score). This protocol was applied to decrease false positive results. The first filter for elimination of false positive results ( $\delta$ value) was applied to the results provided by AutoDock Vina program. The Complex 1W6M-ZINC69482333, 2QHN-ZINC01721695, and 3JYA-ZINC01557254 were those with the largest delta values, and therefore were subjected to energy minimization and molecular dynamics calculations. The Table 1 shows that natural compounds can complex with the targets in all methods studied. In order to improve the docking results the free energy of the complex were carried out using AMBER Score implanted in the Dock6 program. The AMBER score implements molecular mechanics simulations with implicit solvent
(Generalized Born solvation model17) applying the allatom force field AMBER traditional for all protein atoms and the general AMBER force field (GAFF18) for the ligand atoms. After these calculations it was observed that natural compounds showed a better energy value than those displayed by crystallographic ligands. These results showed that the compounds ZINC69482333, and ZINC01721695 ZINC01557254 can bind the molecular targets $1 \mathrm{~W} 6 \mathrm{M}, 2 \mathrm{QHN}$ and 3JYA, respectively.

The intermolecular interactions between ligands and receptors are shown in the figure 3. In the 3D representation the green and pink colour represent hydrogen bond acceptor and donor regions in the binding site, respectively; the green dash lines show hydrogen bonds and hydrophobic interactions. In addition, 2D pharmacophoric map shows van der Waals and electrostatics interactions by green and pink colours, respectively. In this context, the figures $3 a, 3 c$ and $3 e$ depict the 3D intermolecular interactions; whereas the figures $3 \mathrm{~b}, 3 \mathrm{~d}$ and $3 \mathrm{f}$ summarize the 2D pharmacophoric map formed by ligands ZINC69482333, ZINC01721695 and ZINC01557254 with the proteins 1W6M, 2QHN and 3JYA, respectively.

In general, in complex 1W6M - ZINC69482333, the electrostatic interaction occurred with Ser1029, Asn1046, Arg1048, His 1052 and Glu1071. In addition, van der Waals interactions were carried out with Val1031, His1044, Asn1061, Trp1068 and Gly1069. Furthermore, a pi-stack interaction was formed between amino acid Trp1068 and aromatic moiety of ligand ZINC69482333 in the protein $1 \mathrm{~W} 6 \mathrm{M}$ protein.

Similar, the intermolecular interaction standard was observed for the interaction between ZINC01721695 and 2QHN. The electrostatic interactions can be observed

Table 1. Binding energy and $\delta$ value of the selected compouds.

\begin{tabular}{|c|c|c|c|c|c|}
\hline & & & \multicolumn{3}{|c|}{ Energy $(\mathrm{kcal} / \mathrm{mol})$} \\
\hline Molecular Target & Ligand & $\delta$ Value & Autodock Vina & Dock (standard) & Dock (AMBER) \\
\hline \multirow[t]{2}{*}{$1 \mathrm{~W} 6 \mathrm{M}$} & Crystallographic & \multirow[t]{2}{*}{1.44} & -4.3 & -26.74 & -18.93 \\
\hline & ZINC69482333 & & -6.2 & -33.54 & -26.55 \\
\hline \multirow[t]{2}{*}{$2 \mathrm{QHN}$} & Crystallographic & \multirow[t]{2}{*}{1.19} & -7.4 & -37.56 & -46.08 \\
\hline & ZINC01721695 & & -8.8 & -41.43 & -47.41 \\
\hline \multirow[t]{2}{*}{ 3JYA } & Crystallographic & \multirow[t]{2}{*}{1.11} & -8.4 & -33.59 & -64.00 \\
\hline & ZINC01557254 & & -9.3 & -35.92 & -77.94 \\
\hline
\end{tabular}


with Leu15, Glu91. On the other hand, van der Waals interactions were carried out with Gln13, Val23, Ala36, Leu137, Leu84, Glu85, Tyr86, Cys87 (Figure 3c and $3 d)$. Additionally, Figure 2d highlights a hydrogen bond between a water molecule and the ligand.

Finally, figure $3 \mathrm{e}$ and $3 \mathrm{f}$ shows the interactions of ZINC01557254 with the 3JYA molecular target. The

a)

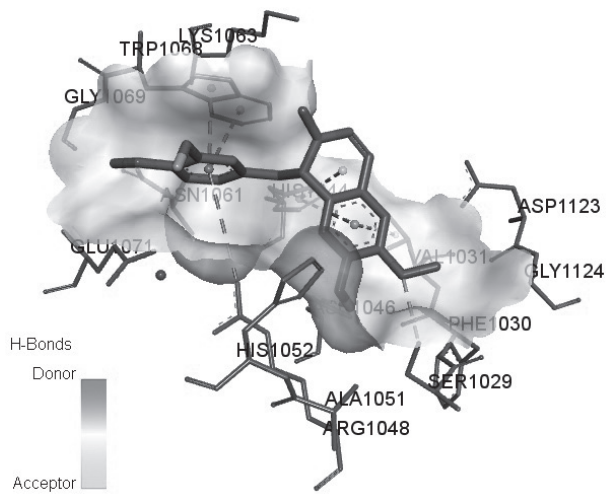

b)

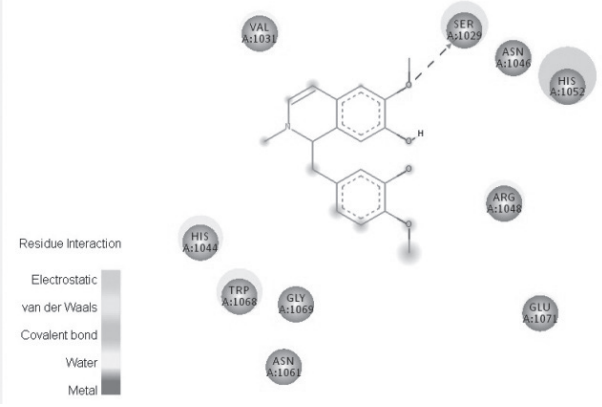

c)

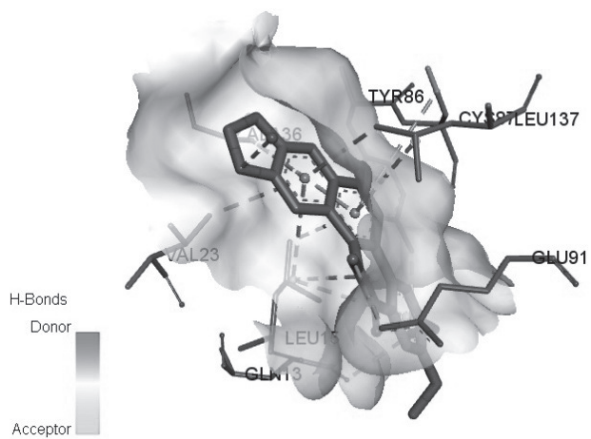

electrostatic interaction occurred with Lys76, Val126 and Asp186. Besides, van der Waals interactions were carried out with Leu44, Gly45, Ala65, Ile104, Leu120, Glu124, Asp131, Leu174 and Ile185. Additionally, in Figure 2f possible to visualize the formation of $\mathrm{Pi}$ interactions between two amino acids (Leu 44 and Ile185) and 3JYA binding site of the protein).

d)
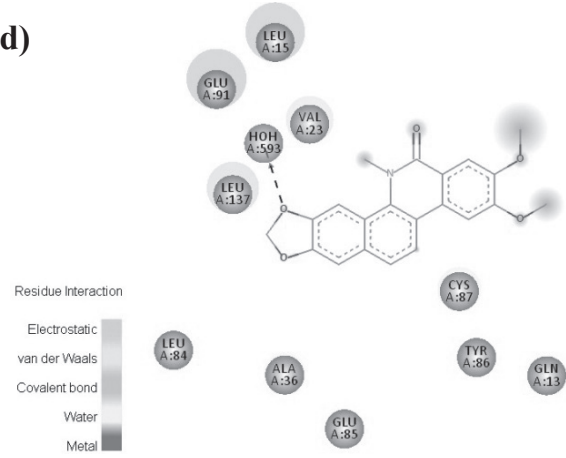

CVS
$A: 37$

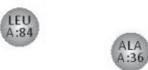

(AYR

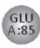

e)

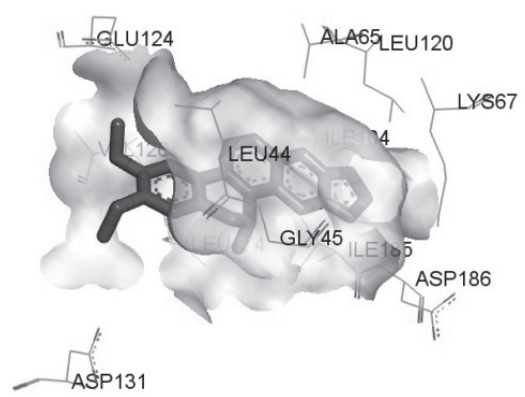

f)

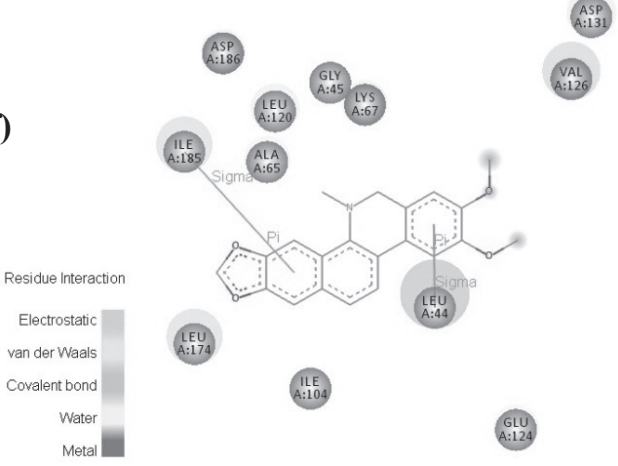

Figure 3. ) ligand ZINC69482333 - 1W6M in 3D; b) ligand ZINC69482333 - 1W6M in 2D; c) ligand ZINC01721695 - 2QHN in 3D d) ligand ZINC01721695 - 2QHN in 2D; e) ZINC01557254 - 3JYA in 3D; f) ZINC01557254 - 3JYA in 2D. 


\section{Conclusions}

Among 473 natural compounds studied using OOMT data base, three of them showed a binding energy profile better than the crystallographic ligands. The calculation of free energy has shown that natural compounds can complex with molecular targets $1 \mathrm{~W} 6 \mathrm{M}$, $2 \mathrm{QHN}$ and 3JYA. Consequently, new hits were formed in drug discovery context. These findings suggested the respective molecular target for these natural compounds. Further, a ligand optimization process can be initiated as a cycle between semi-synthesis and biological assay improving the anticancer property.

\section{Acknowledgments}

The authors are grateful for the support given from the FAPEMIG (APQ-00557-14), CAPES, CNPq (UNIVERSAL 449984/2014-1) and PPGCF/UFSJ .

\section{References}

1. R. S. Ferreira and B. Oliva, Quim. Nova, 34, 1770, (2011).

2. M. S. Butler, J. Nat. Prod., 67, 2141, (2004).

3. A. P. Carregal, M. Comar Jr, A. G. Taranto, Biochem. Biotechnol. Reports, 2, 14, (2013).

4. J. J. Irwin, T. Sterling, M. M. Mysinger, E. S. Bolstad, R. G. Coleman, J. Chem. Inf. Model, 52, 1757, (2012).

5. A. K. Rappe, C. J. Casewit, K. S. Colwell, W. Goddard, W. M. Skiff, J. Am. Chem. Soc., 114, 10024, (1992).

6. M. J. Frisch, G. W. Trucks, H. B. Schlegel, G. E. Scuseria, M. A. Robb, J. R. Cheeseman, G. Scalmani, V. Barone, B. Mennucci, G. A. Petersson, H. Nakatsuji, M. Caricato, X. Li, H. P. Hratchian, A. F. Izmaylov, J. Bloino, G. Zheng, J. L. Sonnenberg, M. Hada, M. Ehara, K. Toyota, R. Fukuda, J. Hasegawa, M. Ishida, T. Nakajima, Y. Honda, O. Kitao, H. Nakai, T. Vreven, J. A. Montgomery, Jr., J. E. Peralta, F. Ogliaro, M. Bearpark, J. J. Heyd, E. Brothers, K. N. Kudin, V. N. Staroverov, R. Kobayashi, J. Normand, K. Raghavachari, A. Rendell, J. C. Burant, S. S. Iyengar, J. Tomasi, M. Cossi, N. Rega, J. M. Millam, M. Klene, J. E. Knox, J. B. Cross, V. Bakken, C. Adamo, J. Jaramillo, R. Gomperts, R. E. Stratmann, O. Yazyev, A. J. Austin, R. Cammi, C. Pomelli, J. W. Ochterski, R. L. Martin, K. Morokuma, V. G. Zakrzewski, G. A. Voth, P. Salvador, J. J. Dannenberg, S.
Dapprich, A. D. Daniels, Ö. Farkas, J. B. Foresman, J. V. Ortiz, J. Cioslowski, and D. J. Fox, Gaussian, Inc., Wallingford CT, 2009.

7. O. Trott and A. J. Olson, J. Comput. Chem., 31, 455, (2010).

8. B. D. Bursulaya, M. Totrov, R. Abagyan, C. L. Brooks, J. Comput. Aided. Mol. Des., 17, 755, (2004).

9. Accelrys Software Inc., Discovery Studio Modeling Environment, Release 3.1, San Diego: Accelyrs Software Inc., 2009.

10. G. Lauro, A. Romano, R. Riccio, G. Bifulco, J. Nat. Prod., 74, 1401, (2011).

11. Inc.. All Rights Reserved. Copyright (C) 2008 Scientific Data Systems Inc.. All Rights Reserved. (2008).

12. W. P. Walters, M. Murcko, Adv. Drug Deliv. Rev., 54, 255, (2002).

13. P. T. Lang, S. R. Brozell, S. Mukherjee, E. F. Pettersen, E. C. Meng, V. Thomas, R. C. Rizzo, D. Case, T. L. James, I. D. Kuntz, RNA, 15, 1219, (2009).

14. M. F. López-Lucendo, D. Sólis, S. A. J. Hirabayashi, K. Kasai, H. Kaltner, H. Gabius, A. Romero, J. Mol. Biol., 343, 957, (2004).

15. E. J. Brnardic, R. M. Garbaccio, M. E. Fraley, E. S. Tasber, J. T. Steen, K. L. Arrington, V. Y. Dudkin, G. D. Hartman, S. M. Stirdivant, B. Drakas, K. Rickert, E. S. Walsh, K. Hamilton, C. Buser, J. Hardwick, W. Tao, S. C. Back, X. Mao, R. B. Lobell, L. Sepp-Lorenzino, Y. Yan, M. Ikuta, S. K. Munshi, L. C. Kuo, C. Kreatsoulas, Bioorganic Med. Chem. Lett., 17, 5989, (2007).

16. R. Amaravadi and C. B. Thompson, J. Clin. Invest., 115, 2618, (2005).

17. A. Onufriev, D. Bashford, D. Case, Proteins Struct. Funct. Genet., $55,383,(\mathbf{2 0 0 4})$.

18. J. Wang, R. M. Wolf, J. W. Caldwell, P. A Kollman, D. A. Case, J. Comput. Chem., 25, 1157, (2004).

\section{Ana Paula Carregal* , Flávia V. Maciel, Juliano B. Carregal \& Alex G. Taranto}

Universidade Federal de São João del Rei - campus Centro-Oeste 35501-296, Divinópolis-MG, Brazil.

*E-mail: anapaulacarregal@gmail.com 